\title{
Baller-Gerold syndrome associated with congenital portal venous malformation
}

\author{
Ravi Savarirayan, Paul Tomlinson, Elizabeth Thompson
}

\begin{abstract}
We report a 4 year old boy in whom the clinical features of craniosynostosis and bilateral absent radii led to a diagnosis of Baller-Gerold syndrome. Additional congenital abnormalities included midface hypoplasia, atrial and ventricular septal defects, right hydronephrosis, partial sacral agenesis, and anterior ectopic anus. Evidence of portal venous hypertension was present from 8 months and a congenital portal venous malformation was discovered at 2 years.

This is the first reported case of BallerGerold syndrome associated with a congenital portal venous malformation. We discuss the diagnostic confusion between this syndrome and other overlapping malformation syndromes and propose optimal evaluation strategies aimed at clarifying the nosology of these syndromes.

( $F$ Med Genet 1998;35:767-769)
\end{abstract}

Keywords: Baller-Gerold syndrome; portal venous malformation

The association of craniosynostosis and preaxial upper limb malformations was first reported by Baller in a 26 year old woman with turricephaly, short stature, right radial aplasia, and left radial hypoplasia. Her parents were third cousins twice removed. Gerold ${ }^{2}$ reported a 16 year old boy and his infant sister who both had turricephaly and bilateral absent thumbs and radii. Cohen ${ }^{3}$ suggested the name BallerGerold syndrome (BGS) to encompass the combination of craniosynostosis and preaxial upper limb malformations, and to date at least 23 patients have been reported. ${ }^{12}$ 4-18

The BGS phenotype is extremely variable with expression in many systems (table 1 ). The condition is inherited in an autosomal recessive manner.

Table 1 Manifestations of BGS in 24 patients *

Paediatrics, Southland

Hospital, Invercargill, New Zealand

P Tomlinson

Correspondence to: Dr Savarirayan, Victorian Clinical Genetics Service, Royal Children's Hospital Parkville, Victoria 3052, Australia.

Received 28 August 1997 Revised version accepted for publication 23 February
Urogenital defects

Cardiac defects

Central nervous system defects

Mental retardation

${ }^{\star}$ Refs $1,2,4-18$, and our case.

$24(100)$
$19(79)$
$13(54)$
$9(38)$
$11(46)$
$10(42)$
$7(29)$
$6(25)$
$5(21)$

\section{Case report}

A 4 year old boy was referred for genetic assessment. He was the product of an in vitro fertilisation pregnancy, born to unrelated parents at 38 weeks by elective caesarean section because of placenta praevia. Multiple congenital abnormalities were noted and comprised ridged metopic suture, midface hypoplasia, bilateral radial agenesis with absent thumbs, atrial and ventricular septal defects, right hydronephrosis, partial sacral agenesis, and anterior ectopic anus. Growth parameters at birth were weight $2950 \mathrm{~g}$ (25th centile), head circumference $35 \mathrm{~cm}$ (50th centile), and length $49 \mathrm{~cm}$ (50th centile). Blood karyotype was normal male, 46,XY. A diagnosis of VACTERL syndrome was made.

At 4 months his head shape was noted to be unusual and premature fusion of the metopic and both coronal sutures was seen on skull $x$ ray; a craniectomy was performed when he was 8 months. At this time it was noted that he had splenomegaly with evidence of hypersplenism (manifested by thrombocytopenia) but no specific cause was found to explain these findings. At 15 months he was seen by a geneticist who raised the possibility of BGS or Fanconi anaemia as possible diagnoses. No evidence of spontaneous or inducible chromosome breaks were seen on specific testing and the diagnosis of BGS was made.

At 2 years of age he had a large gastrointestinal haemorrhage secondary to oesophageal varices discovered on upper gastrointestinal endoscopy. Liver function tests and blood clotting studies were normal and a thorough search was performed looking for indications of primary liver disease. This included a sweat test, serology for hepatitis $B, C$, and cytomegalovirus, serum copper studies, $\alpha$-l-antitrypsin protein electrophoresis, and liver biopsy, all of which were normal. An abdominal ultrasound examination showed a spleen $11 \mathrm{~cm}$ in length (normal $<7 \mathrm{~cm}$ ) with hepatopetal flow in the splenic vein. A subsequent portal vein study showed appearances consistent with cavernous transformation of the portal vein high up in the porta hepatis, indicating previous portal vein obstruction.

At referral (4 years) his weight and height were at the 25 th centile for age $(15.8 \mathrm{~kg}$ and $101 \mathrm{~cm}$, respectively) with head circumference at the 97 th centile $(53.5 \mathrm{~cm})$. He had a ridged metopic suture, hypotelorism, wide nasal bridge (fig 1), and radial clubbed hands with absent thumbs (fig 2 ). An anteriorly sited anus, pes planus, and the clinical findings of portal hypertension and a ventricular septal defect 


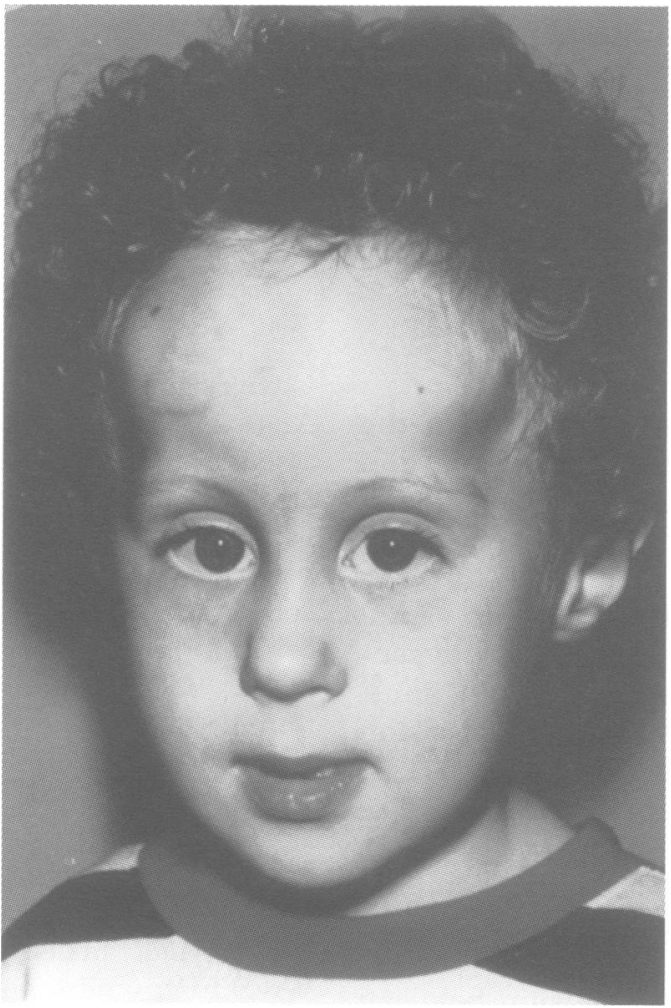

Figure 1 The proband aged 4 years. Note ridged metopic suture, hypotelorism, and prominent nasal bridge. (Photograph reproduced with permission.)

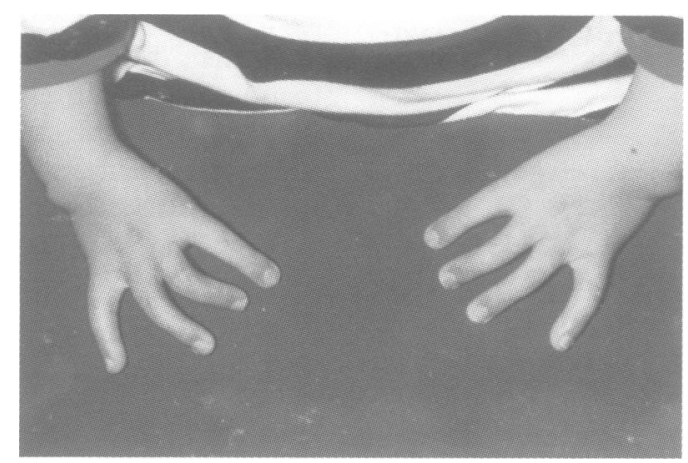

Figure 2 Note bilateral radial agenesis with absent thumbs.

were also present. His development was normal for age.

In the light of the paper by Huson et al, ${ }^{19}$ cytogenetic analysis was repeated (on $\mathrm{G}$ and $\mathrm{C}$ banded preparations) to look for heterochromatin repulsion. On the first culture, $C$ banded preparations showed variants displaying a degree of heterochromatin repulsion but subsequent cultures failed to reproduce this finding. The normal male karyotype was confirmed. There was no evidence of increased spontaneous chromosome instability or abnormal chromosome hypersensitivity on testing with diepoxybutane compared to controls.

\section{Discussion}

The combination of craniosynostosis affecting various sutures and preaxial upper limb defects is characteristic of BGS. Recently, however, several authors, including Cohen and Toriello, ${ }^{20}$ who initially coined the term "Baller-Gerold" syndrome, have questioned whether BGS is a distinct entity. The wide phenotypic variability seen in BGS and other overlapping conditions, such as Fanconi anaemia, Roberts syndrome (RS), and the VACTERL association, make it difficult to clarify the nosology in many cases. Our patient illustrates this confusion, with the initial diagnosis being VACTERL association which was subsequently changed to BGS.

In recent medical publications there are several examples of diagnostic confusion among these phenotypically similar entities. Fanconi anaemia was diagnosed in a child previously reported by Lewis $e t a l^{21}$ to have BGS. This child was born with multiple birth defects including hydrocephalus, growth retardation, and cardiac, anal, and limb abnormalities. Craniosynostosis (right lambdoid) was also reported. Chronic thrombocytopenia was noted at 3 years and led to the consideration of Fanconi anaemia, which was proven on cytogenetic testing. ${ }^{22}$ Rossbach et $a l^{3}$ reported two brothers diagnosed with BGS (one of whom had previously been diagnosed with the VACTERL association) until severe thrombocytopenia was noted and chromosome testing showed cytogenetic abnormalities consistent with Fanconi anaemia in both children. Huson et $a l^{19}$ reported a 26 year old woman with bicoronal craniosynostosis and bilateral radial and thumb hypoplasia in whom the initial diagnosis was BGS. A skeletal survey performed to investigate short stature showed lower limb abnormalities, and on review of the case the facial phenotype was considered consistent with that of RS. Cytogenetic studies showed heterochromatin "puffing" characteristic of RS. These cytogenetic phenomena were seen on $G$ banded metaphases but were more prominent in $\mathrm{C}$ banded preparations. The authors considered that their proband had a "mild" form of RS and raised the question of whether BGS is a distinct entity or a mild phenotypic expression of $\mathrm{RS}$ and suggested that cases diagnosed as BGS have cytogenetic analysis and that known RS survivors be reviewed for craniosynostosis.

In one BGS case report, the authors cite that craniosynostosis has not been reported in RS in their attempts to differentiate the two conditions. ${ }^{18}$ Craniosynostosis has been described previously in two cases of RS. ${ }^{1924} \mathrm{We}$ therefore suggest that craniosynostosis may well be a manifestation of the wide phenotypic spectrum of RS that has been unreported or not specifically looked for. We suggest that the presence of craniosynostosis should not exclude the diagnosis of RS.

These cases emphasise the potential for error in making a diagnosis of "BGS" or "VACTERL association" in children with this spectrum of anomalies without first excluding conditions such as Fanconi anaemia or RS, which have an overlapping phenotype and a diagnostic test available. Both of these conditions were carefully excluded in our case.

The portal venous malformation described was not associated with any predisposing factors including neonatal sepsis, neonatal umbilical vein catheterisation, surgical or blunt abdominal trauma, extrahepatic biliary lesions, 
chronic liver disease, or a hypercoagulable state. ${ }^{25}$ This, combined with the fact that thrombocytopaenia and splenomegaly was first noted at 8 months of age in this boy, points towards a primary developmental malformation of the portal vein causing portal venous obstruction rather than portal venous thrombosis resulting from a secondary aetiology. Portal venous malformations have not been described previously in BGS and this report expands the phenotypic spectrum of the disorder.

We propose that the optimal evaluation of patients with the spectrum of anomalies described in our patient should include cytogenetic testing for RS and Fanconi anaemia, periodic haematological screening (looking for abnormalities suggestive of Fanconi anaemia that can first present up to 10 years), and a skeletal survey. The reasons for doing this are twofold. Firstly, it will help clarify the nosology of these overlapping conditions until these entities are understood at a molecular level. Secondly, and most importantly, it will allow the appropriate management and family counselling to be given in these cases, as $\mathrm{RS}^{26}$ and Fanconi anaemia ${ }^{27}$ can be detected prenatally and the clinical management in Fanconi anaemia is markedly different from that of RS and BGS.

It is important to note that, although diepoxybutane breakage is the best currently available cytogenetic indicator of Fanconi anaemia, false negatives do occur. This is related to the marked underlying genetic (locus) heterogeneity in the condition with as many as eight complementation groups being described and three genes having been mapped. ${ }^{28}$ Some of these complementation groups do not display cellular hypersensitivity to crosslinking agents such as diepoxybutane. Thus, the potential exists for the diagnosis of Fanconi anaemia to be still theoretically tenable after a negative diepoxybutane test. This is our rationale for advocating "periodic" haematological screening during childhood in these cases, even after a "negative" diepoxybutane test. As more of the genes causing Fanconi anaemia are identified, specific mutation analysis in these suspected patients will become the definitive diagnostic test.

Finally, we agree with Cohen and Toriello ${ }^{20}$ who suggest that the diagnosis of BGS be considered only after careful exclusion of these overlapping entities and propose the above evaluation of all patients with this spectrum of abnormalities.

The authors wish to thank Mr David David, Australian Craniofacial Unit, for referral of the patient and the clinical photographs.
1 Baller F Radiusaplasie und Inzucht. $Z$ Menschl VererbKonstit-Lehre 1950;29:782-90.

2 Gerold M. Frakturheilung bei einem seltenen Fall kongenitaler Anomalie der oberen Gliedmassen. Zbl Chir 1959;84 831-4.

3 Cohen MM Jr. Craniosynostosis and syndromes with craniosynostosis: incidence, genetics, penetrance, variability and new syndrome updating. In: O'Donnell J, Hall BD, eds. Penetrance and variability in malformation syn$\mathrm{BD}$, eds. Penetrance and variability in malfo

4 Greitzner LJ, Jones KI, Schnall BS, Smith DW. Craniosynostosis-radial aplasia syndrome. $F$ Pediatr 1974 84:723-4.

5 Temtamy SA, McKusick VA. Craniosynostosis with radia defects. In: Bergsma D, ed. The genetics of hand malformations. New York: Alan R Liss, 1978:114-47.

6 Feingold M, Sklower SL, Willner JP, Desnick RH, Cohen MM. Craniosynostosis-radial aplasia: Baller-Gerold syndrome. Am $\mathcal{F}$ Dis Child 1979;133:1279-80.

7 Pelias MZ, Superneau DW, Thurmon TF. A sixth report (eighth case) of craniosynostosis-radial aplasia (BallerGerold) syndrome. Am $\mathcal{F}$ Med Genet 1981;10:133-9.

8 Anyane-Yeboa K, Gunning L, Bloom AD. Baller-Gerold syndrome. Craniosynostosis-radial aplasia syndrome. Clin Genet 1980;17:161-6.

9 Woon KC, Kokich VG, Clarren SK, Cohen MM. Craniosynostosis with associated cranial base anomalies: a morphological and histologic study of affected like-sexed twins. Teratology 1980;22:23-35.

10 Arena JP, Carlin ME. A further delineation of Baller-Gerold syndrome. Am f Med Genet 1988;34:135

11 Jakobeit M, Stengel-Rutkowski S. Kraniosynostosisradiusdysplasie-syndrom (Baller-Gerold syndrom). Sozialpädiatrie in Praxis und Klinik 1988;10:510-19.

12 Boudreaux JM, Colon MA, Lorusso GD, Parro EA, Pelias MZ. Baller-Gerold syndrome: an 11 th case of craniosynostosis and radial aplasia. Am $\mathcal{F}$ Med Genet 1990;37:447-50.

13 Galea P, Tolmie JL. Normal growth and development in a child with Baller-Gerold syndrome (craniosynostosis and radial aplasia). f Med Genet 1990;27:784-7.

14 Dallapiccola B, Zelante L, Mingarelli R, Pellegrino M, Bertozzi V. Baller-Gerold syndrome: case report and radiological review. Am f Med Genet 1992;42:365-8.

15 Van Maldergem L, Verloes A, Lejeune L, Gillerot Y. The Baller-Gerold syndrome. F Med Genet 1992;29:266-8.

$16 \mathrm{Lin}$ AE, McPherson E, Nwokoro NA, Clemens M, Losken HW, Mulvihill J. Further delineation of the Baller-Gerold syndrome. Am $\mathcal{F}$ Med Genet 1993;45:519-24.

17 Reichenbach H, Hörmann D, Theile J. A further case with Baller-Gerold syndrome (craniosynostosis-radial aplasia syndrome): overview and new viewpoints on a rare syndrome. Kinderärztl Praxis 1993;61:161-7.

18 Preis S, Majewski F, Körholz D, Göbel U. Osteosarcoma in a 16-year-old boy with Baller-Gerold syndrome. Clin Dysmorphol 1995;4:161-8.

19 Huson SM, Rodgers CS, Hall CM, Winter RM. The BallerGerold syndrome: phenotypic and cytogenetic overlap with Roberts syndrome. F Med Genet 1990;27:371-5.

20 Cohen MM Jr, Toriello HV. Is there a Baller-Gerold syndrome? Am ₹ Med Genet 1996;61:63-4.

21 Lewis MES, Rosenbaum PL, Paes BA. Baller-Gerold syndrome associated with congenital hydrocephalus. $A m \mathcal{F}$ Med Genet 1991;40:307-10.

22 Farrell SA, Paes BA, Lewis MES. Fanconi anemia in a child previously diagnosed as Baller-Gerold syndrome. $\mathrm{Am} \mathrm{f}$ Med Genet 1994;50:98-9.

23 Rossbach HC, Sutcliffe MJ, Haag MM, Grana NH, Rossi AR, Barbosa JL. Fanconi anemia in brothers initially diagnosed with VACTERI association with hydrocephalus, and subsequently with Baller-Gerold syndrome. Am $f$ Med and subsequently with

24 Holmes-Siedle $M$, Seres-Santamaria A, Crocker $M$, Hall JG, Crouchman M. A sibship with Roberts/SC phocomelia syndrome. Am ₹ Med Genet 1990;37:18-22.

25 Alvarez F, Bernard O, Brunelle F, Hadchouel P, Odièvre M, Alagille D. Portal obstruction in children. Clinical investigation and haemorrhage risk. F Pediatr 1983;103:696-702.

26 Benzacken B, Savary JB, Manouvrier S, Bucourt Gonzales J. Prenatal diagnosis of Roberts syndrome : two new cases. Prenat Diagn 1996;16:125-30.

27 Kwee ML, Lo Ten Foe JR, Arwert F, et al. Early prenatal diagnosis of Fanconi anaemia in a twin pregnancy, using DNA analysis. Prenat Diagn 1996;16:345-8.

28 Joenje $\mathrm{H}$, Oostra AB, Wijker M, et al. Evidence for at least eight Fanconi anaemia genes. Am f Hum Genet 1997;61: 940-4. 